\title{
Research on the Innovation of College English Reading Education based on the Analysis of Language and Cultural Differences
}

\author{
Feng Jie \\ College of International Cooperation, Xi'an International University,Shaanxi,Xi'an, China
}

\begin{abstract}
With the development of global economy, communication based on linguistic and cultural differences has become a part of people's daily life. instruction English reading based on linguistic and cultural differences is an important way to cultivate high-level and international English professionals. In the process of implementing English reading instruction based on linguistic and cultural differences, we should eliminate the prejudices in terms of traditional thinking and cultural views, continuously improve teachers' instruction ability, and reasonably select instruction materials. Moreover, we should design instruction tasks according to students' receptive abilities, and promote high-quality development of reading instruction based on linguistic and cultural differences through exploratory, open and discursive instruction practices.
\end{abstract}

Key words: language and cultural differences, College English, reading teaching, innovation

\section{Introduction}

Colleges and universities are the cradle of training highly qualified English professionals, and reading is a major means for students to learn language. English reading instruction based on linguistic and cultural differences is an important way to cultivate students' English language ability, linguistic and cultural difference ability, thinking ability and humanistic literacy. With the development of global integration, the original English instruction mode has not adapted to the needs of social development. Based on the new era, teachers should clarify the connotation of English reading instruction based on linguistic and cultural differences, deeply understand its important value, and determine scientific instruction strategies closely around the basic instruction content[1].

II. Overview of English reading instruction in colleges and universities based on education of linguistic and cultural differences

1)English reading instruction based on linguistic and cultural differences in colleges and universities.

English reading teaching in colleges and universities is an English reading teaching paradigm that combines language learning and thinking on the basis of reading to improve students' English language ability, language and cultural differences ability, thinking ability and humanistic literacy simultaneously. Reading not only consolidates and strengthens students' basic language skills, but also develops their thinking skills and analytical abilities, making them a high-quality English professional[2].

2) Language and cultural difference competence.

Language and cultural difference competence refers to students' ability to accept, understand and apply the culture of English-speaking countries. Communication based on linguistic and cultural differences is a very important part of English humanities education in colleges and universities. It can cultivate and improve English majors' communicative competence in language and cultural differences, cultivate their sensitivity and self-awareness of language and cultural differences, and enable students to see the world with a broader vision and a higher perspective, so that they can interact with people of different cultural orientations in a more flexible and efficient

ISSN: 0010-8189

www.converter-magazine.info 
way[3-5].

3) Critical thinking.

Speculation is a kind of high-level psychological activity, which refers to the mental activity in which individuals make further solutions or decisions after analyzing and judging events, things or phenomena according to certain standards. Its specific abilities include questioning, reasoning, independent speculation, analysis, evaluation, etc[6-8]

\section{The importance of teaching English reading in colleges and universities based on the education of linguistic and cultural differences}

1) Reading teaching based on linguistic and cultural differences is a strategic need to cultivate international English talents.

With the deepening of reform and opening up, China's international status has gradually improved, and the country's participation in global governance has become more extensive, making the traditional way of teaching English no longer meet the requirements of the times. First, international communication needs more high-quality English talents. Second, as international standards are further improved, English teaching is developing to a deeper and broader perspective. Teachers need to continuously improve their ability to teach language and cultural differences, while students should have the ability to think about language and cultural differences. Third, as international activities become more and more frequent, English professionals should have stronger comprehensive abilities. Fourth, with the increasing expansion of national strategic interests, a large number of English professionals are needed in various industries. English reading teaching based on linguistic and cultural differences helps universities and colleges change their thinking about English talent training, and is an important way to cultivate international English talents.

2) Reading instruction based on linguistic and cultural differences helps to improve students' overall cultural literacy. On the basis of developing students' language skills, reading instruction based on linguistic and cultural differences highlights the development of linguistic and cultural difference competence and critical thinking, which is conducive to improving students' overall literacy. First, it expands students' linguistic and cultural and makes their linguistic and cultural and communication skills more comprehensive. Second, it helps students acquire knowledge of humanities and social disciplines such as literature, social studies, philosophy, and history in English-speaking countries, which substantially improves their linguistic and cultural differences literacy. Third, critical instruction further enhances students' ability to analyze, think, and judge, enabling them to deepen their understanding of relevant cultures.

3) Reading instruction based on linguistic and cultural differences helps to improve students' English comprehension skills.

English is a communication tool, and the prerequisite for communication is understanding, and only by correctly understanding the connotations of each other's words can we achieve efficient communication. Reading instruction based on linguistic and cultural differences, on the one hand, improves students' linguistic and cultural differences literacy and communication skills, thus laying a cultural foundation for improving students' English comprehension. On the other hand, it enhances students' ability to analyze, think and judge. These two aspects form a synergy that can jointly promote the rapid improvement of students' English application skills.

4) Reading instruction based on linguistic and cultural differences helps to improve students' linguistic communication skills.

Reading instruction based on linguistic and cultural differences promotes students' linguistic and cultural difference competence and critical thinking to improve their language communication skills. First, linguistic and cultural differences enrich the cultural heritage of English learning, which not only helps students deepen their understanding of English, but also improves their language expression skills. Second, critical thinking enhances students' English 
application skills, making their language expressions more flexible, diverse, accurate and vivid.

5) Reading instruction based on linguistic and cultural differences can fully stimulate students' interest in learning. Culture is interesting and critical thinking is vivid. There is no doubt that reading instruction based on linguistic and cultural differences makes traditional English teaching richer and more interesting, and can effectively stimulate students' interest in learning English. It also makes the boring English learning more interesting and can stimulate students' desire to learn.

\section{Content of English reading teaching in colleges and universities based on linguistic and cultural differences education}

1)The connotation of words based on linguistic and cultural differences.

The cultural connotation of a language refers to the cultural connotation implied in a single word, idiom, proverb, or motto. In learning English, it is important to pay attention not only to the learning of language forms but also to the learning of cultural connotations of words. Teachers should hold more lectures on the cultural connotations of words and guide students to explore them, so as to enrich the cultural connotations of their own words.

2)The basic context of linguistic and cultural differences.

Basic background culture refers to the social, historical and cultural background of the country where English is the main language, including politics, economy, astronomy, geography, literature and many other aspects. Only when students have really mastered these contents can they make their English level reach a certain height. Otherwise, it will be difficult for them to improve their English after they reach a certain level. Teachers should guide students to establish awareness of linguistic and cultural differences in their teaching, actively learn the background culture of the target country, resolutely avoid using Chinese to measure foreign culture, and reduce or eliminate linguistic communication errors caused by cultural differences.

3)Social customs and values in different English-speaking countries and cultures.

Different cultures have different social customs and values, and this cultural difference can have a great impact on communication. It is well known that different cultures have different taboos, and if students do not know these taboos, misunderstandings may arise during communication. Therefore, an accurate grasp and understanding of the social customs and values of the target country is necessary to facilitate communication quickly.

\section{Strategies for teaching English reading in colleges and universities based on linguistic and cultural differences education}

1)The first goal of reading instruction is to develop students' language ability, linguistic and cultural difference competence and critical thinking.

The determination of teaching objectives is the key to the success of teaching activities. Reading instruction based on linguistic and cultural differences must firmly grasp the three goals of language proficiency, linguistic and cultural difference competence, and critical thinking, so that the three develop in a balanced way and promote each other. In teaching, teachers should pay attention to the development of students' linguistic and cultural difference competence and critical thinking, as well as to the balance between the teaching content and English language, the balance between accurate expression and fluency, and the balance between Chinese and foreign cultures.

2)The second goal of reading instruction is to select teaching materials with a certain cultural background and depth and breadth of thought.

The selection of teaching materials is very important. In English reading instruction based on linguistic and cultural differences, teachers should pay great attention to the selection of teaching materials. First of all, the subject matter of the materials must be important, reflecting the characteristics of the times and meeting the needs of social 
development. Secondly, the selected materials should have a certain cultural background that can help students improve their linguistic and cultural differences literacy. Thirdly, the content of the materials should have a certain depth and breadth of thought and reach the desired height.

3)The development of students' critical thinking skills based on linguistic and cultural differences is an important goal of the reading instruction activity.

Although English reading instruction based on linguistic and cultural differences develops students' three skills, its ultimate goal is to improve students' critical thinking. Therefore, teachers should introduce appropriate contents into their daily teaching to strengthen students' critical thinking skills based on linguistic and cultural differences. On the one hand, teachers need to increase the quantity of relevant materials in order to accumulate the necessary quantity for qualitative change. On the other hand, teachers need to deepen the implementation of teaching and learning to promote the timely occurrence of qualitative change.

4)The teaching methods should be flexible and varied to fully mobilize the learning enthusiasm of students.

First of all, teachers should introduce and permeate the awareness of cultural and cultural differences in English teaching, introduce and explain culture-specific contents to students, and avoid unnecessary misunderstandings due to cultural differences in communication. Secondly, teachers should be good at cultivating students' awareness of cultural and cultural differences by using the method of cultural comparison to avoid mistakes in their understanding. Thirdly, teachers should strengthen the implantation of cultural background knowledge to better improve the efficiency of English teaching. Fourthly, teachers should guide students to understand different cultures through language practice and try their best to improve students' language communicative competence.

5) Teachers' teaching ability based on linguistic and cultural differences should be continuously cultivated and improved.

Teachers are the subjects of reading instruction based on linguistic and cultural differences. If we want to improve the teaching effect, we must first enhance the teaching ability of teachers. Schools should encourage teachers to actively participate in various activities such as English training, special seminars and teaching open week, so as to help teachers constantly improve their teaching ability. First, schools should enrich the comprehensive cultural quality of teachers. Second, the school should change teachers' teaching concepts and help them establish their consciousness of linguistic and cultural differences and critical thinking. Third, schools should guide teachers to innovate teaching methods and make them constantly improve themselves in innovation.

6) The assessment of students' linguistic competence, linguistic and cultural difference competence and critical thinking is an important indicator in the evaluation of reading instruction. The effectiveness of teaching evaluation directly affects the motivation of teachers and students. Schools should determine scientific and reasonable assessment indicators, and include students' language ability, linguistic and cultural difference competence and critical thinking in the assessment and evaluation of teaching, so as to stimulate teachers' motivation to teach and students' motivation to learn. First, the school should clarify the reasonable proportion of language proficiency, linguistic and cultural difference competence and critical thinking, and balance the teaching plan. Second, valid parameters should be extracted separately to make the assessment of the three competencies objective, fair and just.

\section{Conclusion}

The goal of teaching in colleges and universities is to cultivate complex, applied and high-quality English talents, and reading is a major means for students to learn language. This paper scientifically elaborates the concept and connotation of English reading instruction based on linguistic and cultural differences, and summarizes six teaching strategies based on the content of reading instruction based on linguistic and cultural differences, in order to provide reference for future teaching work. 


\section{Acknowledge}

1,The study was supported by 2018 Scientific Research Project of Education Department of Shaanxi Provincial Government "A Study of English Critical Reading in College under the Background of Intercultural Education" ( Project Number: 18JK1125)

2, The project is supported by the 2020 "Thirteenth Five-Year Plan" Project of Shaanxi Provincial Institute of Education and Science "Research on the Course Construction of 'Integrated English' for English Major Based on 'Production-oriented Approach"” (Project Number: SGH20Y1427)

3, The project is supported by the 2021 Federation of Social Sciences in Shaanxi Province "An Exploration of Ideological and Political Education in College English Reading Based on 'Production-oriented Approach'"(Project Number 2021HZ0736).

\section{Reference}

[1] Zheng Zhong. Comparative analysis of Chinese and English cultural differences and teaching countermeasures from a cross-cultural perspective [D]. Liaoning Normal University, 2013

[2] Statement. Analysis of English Chinese idiom translation from English Chinese language and cultural differences [J]. Journal of Xinzhou Normal University, 2010 (01): 131-133

[3] Yang Shasha. Analysis of language and cultural differences in international business communication [J]. Statistics and management, 2015, 000 (001): 148-148149

[4] Zhang Yu. Analysis of Japanese translation from the perspective of language and cultural differences [J]. Urban Tutor: the first half of the month, 2012 (10): 207-208

[5] Zhang Ruihua. Analysis of cultural differences in translation and translation strategies [J]. Friends of middle school English: Research on foreign language learning and teaching methods, 2018 (1): 26-26

[6] Cui Qimin. Analysis of cultural differences and language translation barriers [J]. Journal of Wuhan University of Technology: Social Science Edition, 2004, 17 (003): 380-382

[7] Ma Huan. Analysis of the impact of Chinese and Western cultural differences on English translation [J]. Going abroad and employment (employment Edition), 2011 (2): 88-90

[8] Jiang Yiyong. Cultural differences and causes of the use of numbers in English and Chinese [J]. Journal of Nanjing audit institute, 2007, 4 (002): 81-86 